\title{
Azimuthally invariant phase tomography of optically anisotropic sections of biological tissues
}

\author{
M.I. Sidor ${ }^{1}$, A.O. Karachevtsev ${ }^{1}$, V.P. Prysyazhnyuk ${ }^{2}$ \\ ${ }^{1}$ Chernivtsi National University, Optics and Publishing Department \\ 2, Kotsyubinsky str., 58012 Chernivtsi, Ukraine \\ ${ }^{2}$ Bukovinian State Medical University, 58000 Chernivtsi, Ukraine \\ E-mail:a.dubolazov@chnu.edu.ua
}

\begin{abstract}
Considered in this work is the theoretical background of the azimuthally stable method of Jones matrix mapping applied to histological sections of uterine neck biopsy based on spatial-frequency selection of the mechanisms responsible for linear and circular birefringence. The comparative results of measuring the coordinate distributions of the complex degree of mutual anisotropy formed by fibrillar networks of myosin and collagen fibrils of uterine neck tissue being in different pathological states - pre-cancer (dysplasia) and cancer (adenocarcinoma) - have been shown. The values and ranges of the change in the statistical (moments of the $1^{\text {st }}$ to $4^{\text {th }}$ orders) parameters of the complex degree of mutual anisotropy of coordinate distributions have been studied. The objective criteria for diagnostics of pathology and differentiation of its severity degree have been determined.
\end{abstract}

Keywords: phase tomography, biological tissues, birefringence.

Manuscript received 10.11.14; revised version received 27.02.15; accepted for publication 27.05.15; published online 08.06.15.

\section{Introduction}

Historically, the optical methods for diagnostics of biological objects may be separated into two groups:

- $\quad$ the spectrophotometric methods [1-3] that are based on analysis of spatial or time changes of the radiation field intensity scattered by biological tissues;

- $\quad$ polarizing methods that are based on the usage of the coherency matrix of complex amplitude.

The correlation methods are based on analysis of the correlation degree of the parallel polarization components of light fluctuation in different points of the object field $[4,5]$.

For the complex azimuthally stable analysis of polarizationally heterogeneous laser radiation fields, a new approach was suggested in [6], based on generalization of the coherence matrix by the polarization coherence matrix for two points.
In [7], to characterize the consistency between the polarization states of the object field in the points with the respective intensities, a new azimuthally stable parameter - the complex degree of mutual polarization (CDMP) - was introduced.

This work is aimed at the development and justification of the method of "point-to-point" Jones matrix mapping and spatial-frequency filtering manifestations of optical anisotropy of benign histological sections (dysplasia - precancerous) and malignant (adenocarcinoma - cancer) tissue of the uterine wall.

\section{Brief theory}

The analysis of processes responsible for amplitudephase modulation of laser radiation by such an object is based on the following assumptions [8]: 
- uterine neck (UN) consists of two optically anisotropic layers of muscle (myometrium) and connective (endometrium) tissues;

- $\quad$ superficial optically anisotropic component of endometrium is formed by disordered by the directions of optical axes collagen fibers $(l \sim$ $5 . .25 \mu \mathrm{m}, L \approx l)$ with prevailing circular birefringence;

- subsurface optically anisotropic network of myometrium is formed by large-scale (range of cross sizes $l \sim 50 \ldots 200 \mu \mathrm{m})$ threadlike $(L>l)$ myosin fibrils with prevailing (due to the order in package that determines the directions of optical axes of partial biological crystals) linear birefringence;

- $\quad$ polarization properties of the points of this fibrillar network are characterized by the generalized matrix of optical anisotropy $\{D\}$

$\{D\}=\{Q\}\{A\}$,

where $\{Q\}$ - Jones matrix of linear birefringence, $\{A\}-$ Jones matrix of circular birefringence or optical activity [9]: $\{Q\}=\|\left[\begin{array}{ll}\left.\sin ^{2} \rho+\cos ^{2} \rho \exp (-i \delta)\right] & {[\sin \rho \cos \rho(1-\exp (-i \delta))]} \\ {[\sin \rho \cos \rho(1-\exp (-i \delta))]} & {\left[\cos ^{2} \rho+\sin ^{2} \rho \exp (-i \delta)\right]}\end{array} \|\right.$,

$$
\{A\}=\left\|\begin{array}{cc}
\cos \theta & -\sin \theta \\
\sin \theta & \cos \theta
\end{array}\right\|,
$$

where $\rho$-direction of optical axis, $\delta=\left(\frac{2 \pi}{\lambda}\right) \Delta n l-$ value of phase shift between orthogonal components of the amplitude of laser waves with the wavelength $\lambda$ that passed the geometrical path $l$ through the biological crystal with linear birefringence $\Delta n, \theta$ - rotation angle of the polarization plane of the laser wave caused by circular birefringence.

In the framework of the "two-point" approach [47], by analogy with the parameter CDMP $V\left(r_{1}, r_{2}\right)$, we can introduce the Jones matrix correlation parameter $W\left(r_{1}, r_{2}\right)$ - the complex degree of mutual anisotropy (CDMA).

It directly characterizes the measure or degree of consistency in linear and circular birefringence points of surface and subsurface tissue.

$W\left(r_{1}, r_{2}\right)=\frac{\left\{d_{11}\left(r_{1}, r_{2}\right)+d_{12}\left(r_{1}, r_{2}\right)+d_{21}\left(r_{1}, r_{2}\right)+d_{22}\left(r_{1}, r_{2}\right)\right\}^{2}}{I\left(r_{1}\right) I\left(r_{2}\right)}$,

Here, $d_{i k}\left(r_{1}, r_{2}\right)$ are the generalized matrix elements of the following form

$$
\left\{\begin{array}{l}
d_{11}\left(r_{1}, r_{2}\right)=d_{11}\left(r_{1}\right) d_{11}\left(r_{2}\right), \\
d_{12}\left(r_{1}, r_{2}\right)=d_{12}\left(r_{1}\right) d_{12}\left(r_{2}\right), \\
d_{21}\left(r_{1}, r_{2}\right)=d_{21}\left(r_{1}\right) d_{21}\left(r_{2}\right), \\
d_{22}\left(r_{1}, r_{2}\right)=d_{22}\left(r_{1}\right) d_{22}\left(r_{2}\right),
\end{array}\right.
$$

where $d_{i k}-$ complex elements of Jones matrix.
Let us determine the spatial-frequency filtering for separation of the coordinate distributions of CDMA formed by various components of the diagnosed UN layer with linear and circular birefringence. From the viewpoint of medicine, the task of "optical selection" of polarization manifestations of linear $(\rho, \delta)$ and circular $(\theta)$ birefringence in the network of protein fibrils typical for UN myometrium and endometrium layers is topical for diagnostics and differentiation of the severity degree of the pathological process. The main idea of this approach is that the spatial-frequency structure of Fourier form of the laser image obtained for the tissue of the uterine wall is different for its large-scale (myosin) and small-scale (collagen) protein structures. Proceeding from this, using spatial-frequency filtration, it is possible to isolate either low-frequency (with linear birefringence) or high-frequency (with circular birefringence) components that by means of Fourier conversion can be transformed into respective "separated" laser images [10]. If we locate the vignetting (transparent $H(\Delta v, \Delta \mu)$ opaque $H^{-1}(\Delta \nu, \Delta \mu)$ ) diaphragm in the central part of Fourier plane, then by means of reverse Fourier transform the low- and highfrequency components can be restored $\left\{\begin{array}{l}\hat{U}(\rho, \delta, \nu, \mu)=R(\Delta v, \Delta \mu) U(\nu, \mu), \\ \dot{U}(\theta, \nu, \mu)=R^{-1}(\Delta \nu, \Delta \mu) U(\nu, \mu) .\end{array} \quad\right.$ Here, $\quad v=\frac{x}{\lambda f} \quad$ and $\mu=\frac{y}{\lambda f}$. Thus, it enables to determine the coordinate distributions of the Jones matrix elements of linear $q_{i k}(\rho, \delta)=F(\hat{U}) \quad$ and circular $\quad a_{i k}(\theta)=F(\dot{U})$ birefringence according to the classical technique [9]. As a result, we obtain analytical expressions of the CDMA parameter for various types of optically anisotropic layers of UN:

$$
\begin{aligned}
& W\left(\rho, \delta, r_{1}, r_{2}\right) \sim \frac{\left\{q_{11}\left(r_{1}, r_{2}\right)+q_{12}\left(r_{1}, r_{2}\right)+q_{21}\left(r_{1}, r_{2}\right)+q_{22}\left(r_{1}, r_{2}\right)\right\}^{2}}{I\left(r_{1}\right) I\left(r_{2}\right)}, \\
& W\left(\theta, r_{1}, r_{2}\right) \sim \frac{\left\{a_{11}\left(r_{1}, r_{2}\right)+a_{12}\left(r_{1}, r_{2}\right)+a_{21}\left(r_{1}, r_{2}\right)+a_{22}\left(r_{1}, r_{2}\right)\right\}^{2}}{I\left(r_{1}\right) I\left(r_{2}\right)} .
\end{aligned}
$$

\section{Experimental results and discussion}

In the experimental part of the research, the following algorithm was used:

\subsection{Determination of statistically reliable representative selection of patients with the known (referent) diagnosis}

As objects of investigation, two groups of optically thin (extinction coefficient $\tau \approx 0.087 \ldots 0.093$ ) histological sections of UN tissue biopsy for two groups of patients with the following diagnoses were prepared according to the standard technique on the freezing microtome: 


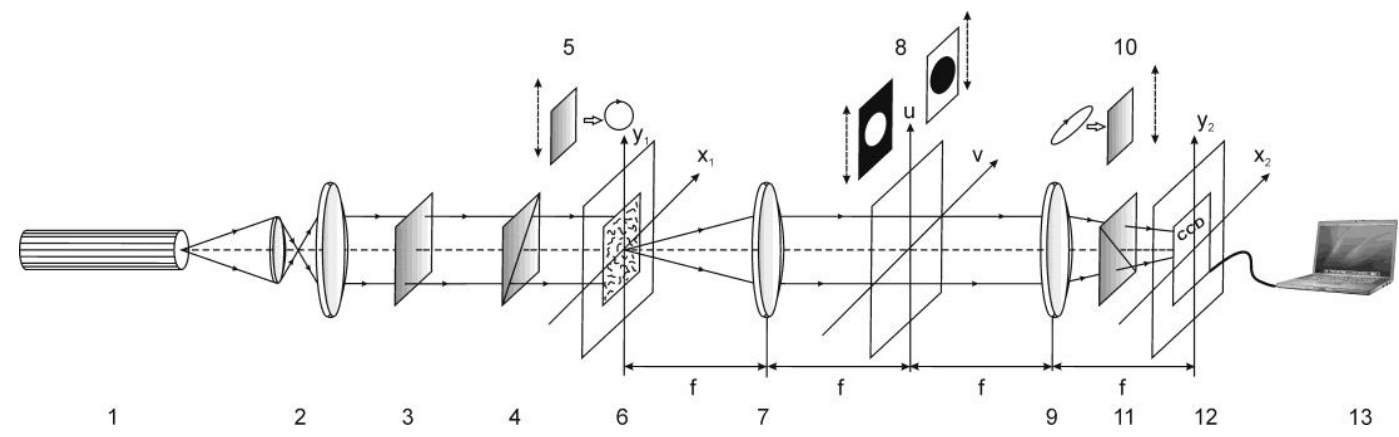

Fig. 1. Optical Stokes polarimeter with using space-frequency filtering, where: 1 - He-Ne laser; 2 - collimator; 3 - fixed quarter-wave plate; 5,10 - mechanically movable quarter-wave disc; 4,11 - polarizer and analyzer, respectively; 6 - the object of investigation; 7, 9-object lens; 8 - low- and high-pass filter, 12 - CCD camera; 13 - PC.

- group 1 - pre-cancer (dysplasia) state,

- group 2 - cancer.

The diagnoses of pre-cancer (group 1) and cancer patients (group 2) were determined using the gold standard method - biopsy of surgically removed tumor. The previously examined donors were included into test group (group 1). By means of software product Statmate for $95 \%$ confidence interval $(p \prec 0.05)$, a reliable quantity of patients was determined: $n=45$.

The magnitude of the representative sample was tested by cross-validation. It was established that the average value of the standard deviation values of the statistical moments $Z_{i=1 ; 2 ; 3 ; 4}$ do not exceed 0.025 , which corresponds to a statistically valid confidence interval $p \prec 0.05$.

3.2. Jones matrix mapping with the spatial and frequency selective coordinate distributions of CDMA of endometrial histological sections

The series of Figs. 2 and 3 presents the results of Jones matrix mapping the low-frequency (linear birefringence of the myometrium) and high-frequency (circular birefringence of the endometrium) distributions of CDMA of the uterine wall histological sections.

\subsection{Statistical intergroup analysis}

For possible clinical application of both methods, the following values were determined for each group of samples [11, 12]:

- $\quad$ average (within group 1 and group 2) values of statistical moments $\bar{Z}_{i=1 ; 2 ; 3 ; 4}(q)$, their standard deviations $\pm \sigma$ and histograms $N\left(\bar{Z}_{i}\right)$ (Table 1).

- traditional for probative medicine operational characteristics $\quad-$ sensitivity $S e=\frac{a}{a+b} 100 \%$, specificity $S p=\frac{c}{c+d} 100 \%$ and balanced accuracy $A c=\frac{S e+S p}{2}$, where $a$ and $b$ are the numbers of correct and wrong diagnoses within the group 2;c and $d$-the same ones within the group 1 (Table 2).
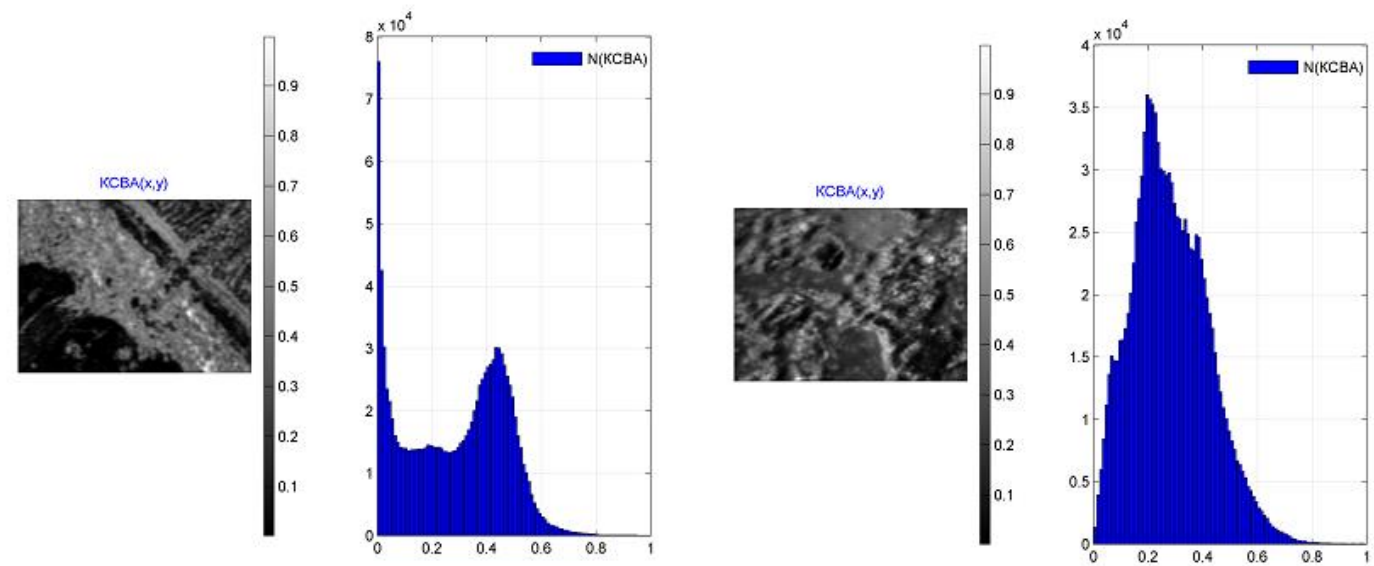

Fig. 2. Low-frequency (linear birefringence of the myometrium) distributions of CDMA of the uterine wall histological sections. 

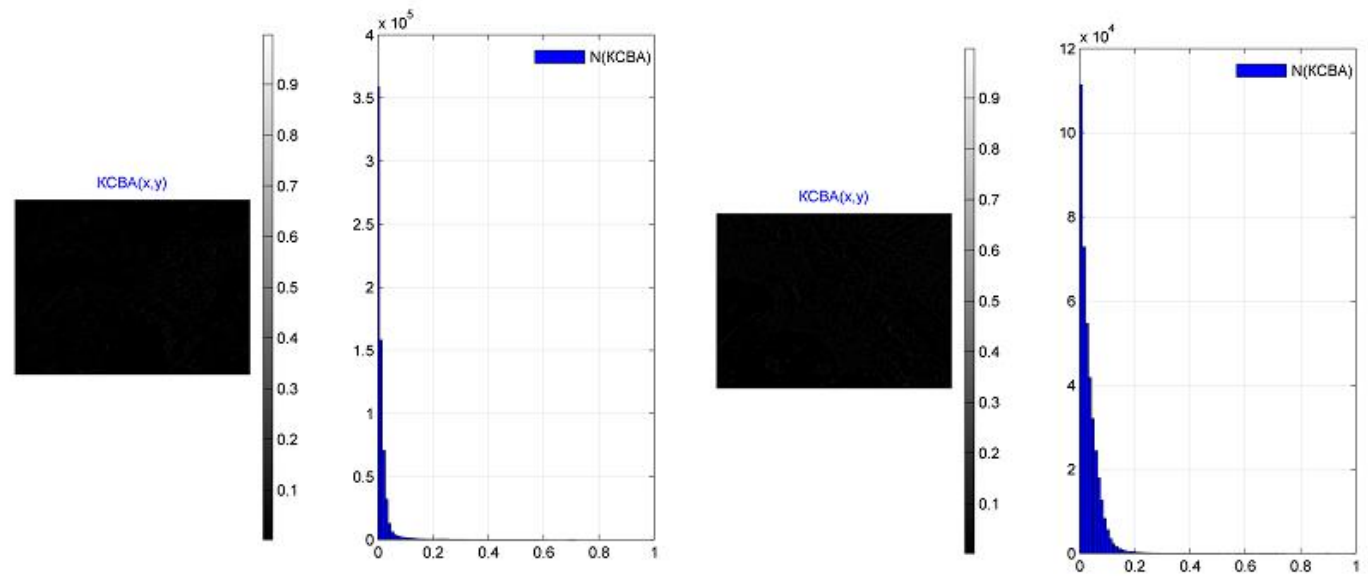

Fig. 3. High frequency (circular birefringence of the endometrium) distributions of CDMA of the uterine wall histological sections.

The comparative analysis of the data obtained (Table 1) showed that the differences between the values of average $\bar{Z}_{i=1 ; 2 ; 3 ; 4}(q)$ moments of all orders are statistically reliable.

Table 2 presents the parameters of the information value obtained using the azimuthally stable method of Jones matrix mapping optical anisotropy of histological sections of the uterine wall biopsies of various pathologies.

Table 1. Parameters of statistical structure of CDMA coordinate distributions.

\begin{tabular}{|c|c|c|c|c|}
\hline \multirow{2}{*}{$\begin{array}{c}\text { Para- } \\
\text { meters }\end{array}$} & \multicolumn{2}{|c|}{$W_{\rho, \delta}(m \times n)$} & \multicolumn{2}{c|}{$W_{\theta}(m \times n)$} \\
\cline { 2 - 5 } & $\begin{array}{c}\text { Dysplasia } \\
n_{1}=45\end{array}$ & $\begin{array}{c}\text { Cancer } \\
n_{2}=45\end{array}$ & $\begin{array}{c}\text { Dysplasia } \\
n_{1}=45\end{array}$ & $\begin{array}{c}\text { Cancer } \\
n_{2}=45\end{array}$ \\
\hline$Z_{1}$ & $0.35 \pm 0.11$ & $0.44 \pm 0.12$ & $0.05 \pm 0.009$ & $0.07 \pm 0.004$ \\
\hline$Z_{2}$ & $0.19 \pm 0.041$ & $0.27 \pm 0.062$ & $0.07 \pm 0.002$ & $0.1 \pm 0.043$ \\
\hline$Z_{3}$ & $1.15 \pm 0.11$ & $0.87 \pm 0.16$ & $0.23 \pm 0.057$ & $0.28 \pm 0.054$ \\
\hline$Z_{4}$ & $0.82 \pm 0.21$ & $0.57 \pm 0.15$ & $1.65 \pm 0.12$ & $1.25 \pm 0.11$ \\
\hline
\end{tabular}

Table 2. Operational characteristics of the method of Jones matrix mapping the optical anisotropy of histological sections taken from the uterine wall biopsy.

\begin{tabular}{|c|c|c|c|}
\hline Parameters & $Z_{i}$ & $W_{\rho, \delta}$ & $W_{\theta}$ \\
\hline \multirow{4}{*}{$S e\left(Z_{i}\right)$} & $Z_{1}$ & $59.7 \%$ & $83.4 \%$ \\
\cline { 2 - 4 } & $Z_{2}$ & $62 \%$ & $81.2 \%$ \\
\cline { 2 - 4 } & $Z_{3}$ & $90.5 \%$ & $62.4 \%$ \\
\cline { 2 - 4 } & $Z_{4}$ & $94.2 \%$ & $66.9 \%$ \\
\hline \multirow{5}{*}{$S p\left(Z_{i}\right)$} & $Z_{1}$ & $54.9 \%$ & $79.8 \%$ \\
\cline { 2 - 4 } & $Z_{2}$ & $58.6 \%$ & $74.6 \%$ \\
\cline { 2 - 4 } & $Z_{3}$ & $88.9 \%$ & $55.6 \%$ \\
\cline { 2 - 4 } & $Z_{4}$ & $91.1 \%$ & $57.8 \%$ \\
\hline \multirow{4}{*}{$A c\left(Z_{i}\right)$} & $Z_{1}$ & $53.25 \%$ & $82.1 \%$ \\
\cline { 2 - 4 } & $Z_{2}$ & $58.8 \%$ & $76.9 \%$ \\
\cline { 2 - 4 } & $Z_{3}$ & $91 \%$ & $62 \%$ \\
\cline { 2 - 4 } & $Z_{4}$ & $93.2 \%$ & $65.35 \%$ \\
\hline
\end{tabular}

The obtained results enable us to state a rather high level of accuracy of azimuthally stable Jones matrix mapping. According to the criteria of probative medicine [4, 5, 14-19], the parameters $R(\theta) \sim 80 \%$ are of good quality, while $R(\rho, \delta) \sim 90 \%$ are of high quality.

\subsection{Prospects of clinical application}

The suggested method can be used to differentiate the temporal changes of the morphological structure of fetal tissues, as based on objective analysis of the orientation (Table 3) and crystalline (Table 4) structure of optically anisotropic networks.

Table 3. Statistical parameters $Z_{i=1 ; 2 ; 3 ; 4}$ that characterize the coordinate distributions of orientation parameter $W_{\rho, \delta}(m \times n)$ histological sections of fetal tissue in different periods.

\begin{tabular}{|c|c|c|c|c|c|c|}
\hline $\begin{array}{c}\text { Para- } \\
\text { meters }\end{array}$ & $\begin{array}{c}5 \\
\text { months }\end{array}$ & $\begin{array}{c}6 \\
\text { months }\end{array}$ & $\begin{array}{c}7 \\
\text { months }\end{array}$ & $\begin{array}{c}8 \\
\text { months }\end{array}$ & $\begin{array}{c}9 \\
\text { months }\end{array}$ & $\begin{array}{c}10 \\
\text { months }\end{array}$ \\
\hline$Z_{1}$ & 0.08 & 0.09 & 0.1 & 0.11 & 0.12 & 0.13 \\
\hline$Z_{2}$ & 0.29 & 0.24 & 0.21 & 0.18 & 0.15 & 0.13 \\
\hline$Z_{3}$ & 0.12 & 0.18 & 0.22 & 0.27 & 0.34 & 0.37 \\
\hline$Z_{4}$ & 0.69 & 0.77 & 0.88 & 1.06 & 1.24 & 1.42 \\
\hline
\end{tabular}

Table 4. Statistical parameters $Z_{i=1 ; 2 ; 3 ; 4}$ that characterized the coordinate distributions of crystallization parameter of histological sections of fetal tissue in different periods.

\begin{tabular}{|c|c|c|c|c|c|c|}
\hline $\begin{array}{c}\text { Para- } \\
\text { meters }\end{array}$ & $\begin{array}{c}5 \\
\text { months }\end{array}$ & $\begin{array}{c}6 \\
\text { months }\end{array}$ & $\begin{array}{c}7 \\
\text { months }\end{array}$ & $\begin{array}{c}8 \\
\text { months }\end{array}$ & $\begin{array}{c}9 \\
\text { months }\end{array}$ & $\begin{array}{c}10 \\
\text { months }\end{array}$ \\
\hline$Z_{1}$ & 0.04 & 0.05 & 0.07 & 0.08 & 0.09 & 0.11 \\
\hline$Z_{2}$ & 0.11 & 0.14 & 0.16 & 0.18 & 0.21 & 0.24 \\
\hline$Z_{3}$ & 0.21 & 0.32 & 0.39 & 0.44 & 0.53 & 0.68 \\
\hline$Z_{4}$ & 0.43 & 0.53 & 0.57 & 0.64 & 0.71 & 0.79 \\
\hline
\end{tabular}




\section{Conclusion}

The comparative investigations of the effectiveness of the developed techniques of spatial-frequency Fourier polarimetry of CDMA in the diagnostics of the pathological state of the UN tissue and differentiation of its severity degree have been carried out.

The criteria of differentiation between the UN dysplasia and cancer on the basis of the statistical (statistical moments of the $1^{\text {st }}$ to $4^{\text {th }}$ orders) analyses of the spatial-frequency filtered distributions of CDMA of protein networks with linear and circular birefringence have been offered.

The method can be used for time monitoring of changes in the orientational structure of crystalline fetal tissues.

\section{Acknowledgement}

This work was supported by the grants № 0113 U003239 and № 0112 U002336 from the Ukrainian Foundation for Basic Researches.

\section{References}

1. V.V. Tuchin, Tissue Optics: Light Scattering Methods and Instruments for Medical Diagnosis, 2nd Ed. PM 166. SPIE Press, Bellingham, WA, 2007.

2. X. Wang, G. Yao, L.-H. Wang, Monte Carlo model and single-scattering approximation of polarized light propagation in turbid media containing glucose // Appl. Opt. 41, p. $792-801$ (2002).

3. X. Wang, L.-H. Wang, Propagation of polarized light in birefringent turbid media: A Monte Carlo study // J. Biomed. Opt. 7, p. 279-290 (2002).

4. E. Wolf, Unified theory of coherence and polarization of random electromagnetic beams // Phys. Lett. A, 312, p. 263-267 (2003).

5. J. Tervo, T. Setala, A. Friberg, Degree of coherence for electromagnetic fields // Opt. Exp. 11, p. 1137 1143 (2003).

6. J. Ellis, A. Dogariu, Complex degree of mutual polarization // Opt. Lett. 29, p. 536-538 (2004).

7. O.V. Angelsky, A.G. Ushenko, Ye.G. Ushenko, Complex degree of mutual polarization of biological tissue coherent images for the diagnostics of their physiological state // J. Biomed. Opt. 10, 060502 (2005).

8. A. Gerrard, J.M. Burch, Introduction to Matrix Methods in Optics. New York, A Wiley-Intersci. Publ., 1975.

9. J.W. Goodman, Statistical properties of laser speckle patters. In: Laser Speckle and Related Phenomena. Ed. J.C. Dainty. Berlin, SpringerVerlag, p. 9-75, 1975.
10. C.S. Davis, Statistical Methods of the Analysis of Repeated Measurements. New York, SpringerVerlag, 2002.

11. O.V. Angelsky, P.V. Polyanskii, C.V. Felde, The emerging field of correlation optics // Optics and Photonics News, 23(4), p. 25-29 (2012).

12. O.V. Angelsky, A.Ya. Bekshaev, P.P. Maksimyak, A.P. Maksimyak, S.G. Hanson, C.Yu. Zenkova, Self-diffraction of continuous laser radiation in a disperse medium with absorbing particles // Opt. Exp. 21(7), p. 8922-8938 (2013).

13. O.V. Angelsky, G.V. Demianovsky, A.G. Ushenko, D.N. Burkovets, Y.A. Ushenko, Wavelet analysis of two-dimensional birefringence images of architectonics in biotissues for diagnosing pathological changes // J. Biomed. Opt. 9(4), p. 679-690 (2004).

14. O.V. Angel'skii, A.G. Ushenko, S.B. Ermolenko, D.N. Burkovets, Yu.A. Ushenko, O.V. Pishak, Polarization-based visualization of multifractal structures for the diagnostics of pathological changes in biological tissues // Optika i Spektroskopiya, 89(5), p. 799-804 (2000), in Russian.

15. O.V. Angelsky, Yu.A. Ushenko, A.V. Dubolazov, O.Yu. Telenha, The interconnection between the coordinate distribution of Mueller-matrixes images characteristic values of biological liquid crystals net and the pathological changes of human tissues // Adv. Opt. Technol., 2010, Article ID 130659, 10 pages (2010).

16. Yu.O. Ushenko, Yu.Ya. Tomka, O.V. Dubolazov, V.O. Balanets'ka, A.V. Karachevtsev, A.P. Angelsky, Wavelet-analysis for laser images of blood plasma // $A E C E$ - Adv. in Electr. and Comput. Eng. 11(2), (2011).

17. V.T. Bachinsky, Yu.O. Ushenko, Yu.Ya. Tomka, O.V. Dubolazov, V.O. Balanets'ka, A.V. Karachevtsev, Wavelet analysis for polarization maps of networks formed by liquid biological crystals in blood plasma: statistical and fractal approaches // Semiconductor Physics, Quantum Electronics \& Optoelectronics, 13(2), p. 189-201 (2010).

18. Yu.A. Ushenko, Yu.Ya. Tomka, A.V. Dubolazov, V.A. Balanetskaya, V.P. Unguryan, N.I. Zabolotna, B.P. Oleinichenko, Mueller-matrix diagnostics of optical properties inherent to polycrystalline networks of human blood plasma // Semiconductor Physics, Quantum Electronics \& Optoelectronics, 14(1), p. 98-105 (2011).

19. Yu.O. Ushenko, O.V. Dubolazov, A.O. Karachevtsev, M.P. Gorsky, Yu.F. Marchuk, Wavelet analysis of Fourier polarized images of the human bile // Appl. Opt. 51, p. C133-C139 (2012). 